Arab Univ. J. Agric. Sci., Ain Shams Univ., Cairo, 13(3), 1019-1031, 2005

\title{
THE PROTECTIVE POTENCY OF GREEN TEA AND GINGER EXTRACTS ON THE GENOTOXIC EFFECT OF MALATHION INSECTICIDE IN BONE MARROW CELLS OF MICE (MUS MUSCULUS)
}

\author{
Ekram F. Hashim ${ }^{1}$ and Ehab M. Abdella ${ }^{2}$
}

\begin{abstract}
In present set of investigations the chemoprotective effect of green tea and ginger extracts has been evaluated using in vivo chromosomal aberrations assay in albino mice (Mus musculus). The organophosphate agropesticide malathion, $80 \%$ technical grade consider as a potent genotoxic agent, was given at a single dose 230 $\mathrm{mg} / \mathrm{kg}$ b.w. (1/12 LD50) intraperitoneally. Pretreatment with 4 and 3\% of freshly prepared green tea (GTI), ginger (GI) extracts, respectively and the mixture of both extracts $(\mathrm{GTI}+\mathrm{GI})$ were given through oral incubation for 6 days prior to malathion administration. Animals from all the groups were sacrified at sampling times of 24 and 48 hours and their bone marrow cells were analyzed for chromosomal damages. The animals of the positive control group (Malathion alone) showed a significant increase in chromosomal aberrations both at 24 and $48 \mathrm{~h}$ sampling time. The green tea and ginger extracts, alone did not significantly induced aberrations at either sampling time, conforming their non-mutagenicity. However, significant suppressions in the chromosomal aberrations were recorded following pretreatment with green tea and ginger extracts administration. The antigenotoxic effects of both extracts separately and in mixture were also evident, as observed by significant increase in mitotic index, when compared to positive control group. Reduction in malathion induced clastogenicity by both extracts, was evident at $24 \mathrm{~h}$ and to a much greater extent at $48 \mathrm{~h}$ of cell cycle. Thus results of the present investigations revealed that green tea and ginger extracts have chemoprotective potential against malathion induced chromosomal mutations in albino mice.
\end{abstract}

Key words: Green tea, Ginger, Genotoxicity, Malathion, Anti-carcinogenic, Albino mice

1- Plant Protection Department, Faculty of Agriculture, Cairo University, Fayoum Branch, Fayoum, Egypt

2- Zoology Department, Faculty of Science, Cairo University, Beni-Sweef Branch, Beni-Sweef, Egypt

(Received March 31, 2005)

(Accepted May10, 2005) 
Arab Univ. J. Agric. Sci., Ain Shams Univ., Cairo, 13(3), 1019-1031, 2005

\section{INTRODUCTION}

Food may contain protective antimutagenic or anticarcinogenic substances, of which most are present in plants, e.g. glucosinolates in vegetables, vitamin $\mathrm{C}$ in fruit, and polyphenolic compounds in green tea and ginger

(DeMarini, 1998).

Inhibition of mutagenesis or carcinogenesis is generally not based on one specific mechanism. Protection against cancer can occur at different stages of the complicated processes of carcinogenesis. Compounds and complex mixtures with antimutagenic activity have different modes of action and act in parallel at different levels. As inhibitors, they may prevent the formation of mutagens, such as the endogenous formation of nitrosamines. As blocking agents, they can prevent the biotransformation of premutagens into reactive metabolites by inhibiting metabolic activation, by stimulating detoxification enzymes, or by scavenging reactive molecules. As suppressing agents, they may modulate intracellular processes, which are involved in DNA repair mechanisms, tumor promotion and tumor progression (Bailey and Williams, 1993 and Krul et al 2001).

Tea (Thea sinensis), the most widely consumed beverage in the world next to water, has drawn attention as a source of antimutagenic compounds. Mechanisms to explain this activity have been proposed and include direct binding to mutagens, modification of metabolic enzymes and antioxidant activity (Weisburger, 1999). Although in animal studies an inhibitory effect of tea on cancer incidence has been observed, the evidence for an effect on human cancer is not conclusive (Kohlmeier et al 1997).

This is partly due to lack of information on the bioavailability in the human digestive tract of the active components in tea, especially in combination with our common diet. Among many polyphenolic compounds isolated from green tea, (-)epigallocatechin gallate (EGCG) is believed to be a key active constituent in terms of cancer chemoprotective potential (Fujiki et al 1992, Komori et al 1993, Fujiki et al 1994, Fujiki et al 1996 and Conney et al 1997). The strong antioxidative activity retained in this polyphenol has been confirmed in numerous in vivo and in vitro studies (Ho et al 1992, Wei and Frenkel, 1993, Lin and Lin, 1997 and Yoshioka et al 1997), which appears to contribute in part to the antimutagenic and anticarcinogenic effects of green tea. Thus, pretreatment of SENCAR mice with EGCG significantly ameliorated TPA-induced infiltration and diminished the formation of hydrogen peroxide and oxidized DNA bases including 8-hydroxy-2'-deoxyguanosine (8-OH-dG) and 5-hydroxymethyl-2'-

1- Plant Protection Department, Faculty of Agriculture, Cairo University, Fayoum Branch, Fayoum, Egypt

2- Zoology Department, Faculty of Science, Cairo University, Beni-Sweef Branch, Beni-Sweef, Egypt

(Received March 31, 2005)

(Accepted May10, 2005) 


\section{Protective potency of green tea and ginger extracts}

deoxyuridine in the skin (Wei and Frenkel, 1993).

Ginger (Zingiber officinale Roscoe) is among the most frequently and heavily consumed dietary condiments throughout the world. Besides its extensive use as a spice, the rhizome of ginger has also been used in traditional oriental herbal medicine for the management of such symptoms as common cold, digestive disorders, rheumatism, neurologia, colic and motion-sickness. The oleoresin from rhizomes of ginger contains [6]-gingerol (1-[4'-hydroxy-3'-methoxyphenyl]-5-

hydroxy-3-decanone) and its homologs as pungent ingredients that have been found to possess many interesting pharmacological and physiological activities, such as anti-inflammatory, analgesic, antipyretic, antihepatotoxic, and cardiotonic effects (Mustafa et al 1993 and Surh 1999).

Malathion, an organophosphate insecticide, is the most commonly used insecticide. According to the U.S.

Environmental Protection Agency (USEPA 2000), there is "suggestive evidence" that Malathion causes cancer. However, recent studies provide stronger evidence: a technical grade malathion insecticide caused breast cancer in laboratory animals, and malathion use by farmers is associated with an increased incidence of a type of cancer, nonHodgkin's lymphoma (Ernst, 2002 and Meulenberg, 2002).

Results from a variety of recent studies are consistent with the genotoxicity and the carcinogenicity of malathion insecticide. Contreras and Bustos-Obregón, (1999) and Giri et al (2002) showed that, malathion given orally caused genetic damage in laboratory mice. Another 2002 study, from Egypt's National Research Center, showed that mice fed with stored wheat that had been treated with a commercial malathion insecticide developed two kinds of genetic damage. The damage occurred at all dose levels tested in this study (Amer et al 2002). Blasiak and Stankowska (2001) showed that malathion, its oxygen analogue malaoxon, and its isomer isomalathion cause genetic damage in human cells.

The aim of this study was to investigate the protective effects of aqueous extracts of green tea and ginger, which they used separately or in mixture, on the genotoxic effect of malathion insecticide in albino mice using cytogenetic end points.

\section{MATERIAL AND METHODS}

\section{Green tea and ginger extracts}

The green tea (GTI) and ginger (GI) infusions were freshly prepared everyday for the duration of in vivo study (4 $\mathrm{g}$ of green tea leaves $/ 100 \mathrm{ml}$ hot water and $3 \mathrm{~g}$ of ginger rhizomes/100 $\mathrm{ml}$ hot water). The concentrations of the natural extraction used in the present study were selected with reference to concentration range that has been used in previously published papers (Surh, 1999 and Gupta et al 2002). The green tea leaves and the ginger rhizomes were procured from local traditional oriental medicine market.

\section{Chemicals}

Malathion[S-(1,2-dicarboethoxyethyl) O,O-dimethyl phosphorodithioate]technical grade $(80 \%$ purity and the remainder $20 \%$ is other Malathion metabolic products as malaoxon [S-(1,2- 
dicarboethoxyethyl)O,O-dimethyl phosphoro-thiolate] and its isomer isomalathion [S-(1,2-dicarboethoxyethyl) O,S-dimethyl phosphorodithioate]- has been supplied by Ministry of Agriculture, Land Reclamation Branch, while Colchicine was obtained from SigmaAldrich Chimie (Saint-Quentin Fallavier, France). All other chemicals used in the study were analytical grade.

\section{Experimental animals}

The experimental animals used in this work were adult males of the laboratory albino mice Mus musculus (18-28 $\mathrm{g}$ in weight). Animals were obtained from Giza Research Center of Optic Diseases. All animals were housed in plastic cages with wired covers and kept under normal laboratory conditions for different periods. The animals were fed on the standard commercial diet (ATMID company, Egypt), and provided with tap water.

\section{Treatment schedule}

The pre-treatment of animals with GTI, GI or GTI + GI mixture were performed along with malathion posttreatment to male mice. The animals were divided in to seven groups of 10 animals each. The animals of the group I were used as a control and no treatment was given. The animals of groups II and III were treated by GTI and GI respectively, through oral intubation for six days consecutively. The animals of the group IV were served as positive control and only malathion was given at the single dose of $230 \mathrm{mg} / \mathrm{kg}$ body weight (corresponding to $1 / 12$ LD50) intraperitoneally. The dose used in the present study was selected with reference to the LD50 and the dose range that has been used in previously published papers dealing with the mutagenicity of malathion in mice (Salvadori et al 1988 and Blasiak et al 1999). While the animals of the groups V, VI and VII, were given the pre-treatment of GTI, GI and GTI+GI respectively, through oral intubation for six days consecutively, and malathion treatment was given after 1 hour of the last dose of GTI, GI or GTI + GI mixture on the $6^{\text {th }}$ day, as a single dose of $230 \mathrm{mg} / \mathrm{kg}$ b.w. intraperitoneally.

After completion of the treatment period, five animals from each group were sacrified at sampling time of $24 \mathrm{~h}$ rest were sacrified at $48 \mathrm{~h}$, by cervical dislocation, Colchicine was given at the dose of $4 \mathrm{mg} / \mathrm{kg} \mathrm{b}$.w. intraperitoneally at 22 and $46 \mathrm{~h}$ respectively prior to sacrificing the animals. The bone marrow smears of animals in each group were prepared as per protocol of Preston et al (1987). Slides were stained with Giemsa and well spread metaphases were analyzed for chromosomal aberrations. Mitotic index and Incidence of aberrant cells (in percentages) for each group were analyzed.

Also \% suppressed aberrant cells were calculated as: $100-(\%$ aberrant cells in each GTI, GI or GTI+GI mixture pretreated and malathion post-treated groups $/ \%$ aberrant cells in positive control (malathion treated) group) X 100.

\section{Statistical analysis}

The data was analyzed for mean values and standard error for all groups, which were subjected to statistical comparison using student-t-test $\mathrm{P}<0.01$, was considered significant. 


\section{RESULTS}

The results revealed that malathion when given at a single dose of $230 \mathrm{mg} / \mathrm{kg}$ b.w., once only (Gr.IV) caused a high incidence of all types of chromosomal aberrations in albino mice, including chromatid breakage, centromeric attenuation, centric fusion, end to end association, polyploidy and endomitosis. The mitotic index and the incidence of aberrant cells were decreased by $40.40 \%$ and increased by $27.00 \%$, respectively, compared to control Gr.I $(\mathrm{P}<0.01)$, indicating bone marrow cytotoxicity. However, each of green tea and ginger extracts (Gr.II and Gr.III, respectively) induced the lowest count of chromosomal aberrations significantly confirming its non-mutagenicity (Tables $1 \& 2$ ). Also, these extracts showed no cytotoxic effects, as there were no significant changes in the mitotic index and the incidence of the aberrant cells compared to the control group I (Fig. 1).

Moreover, when pretreatment of different extracts (GTI, GI and GTI+GI) was given prior to malathion treatment (in groups V, VI and VII, respectively), decreased rates of clastogenic changes were observed (Tables 1\&2). All types of chromosomal aberrations induced by malathion, including breaks and other multiple damages were found to be reduced by GTI, GI and GTI+GI. The status of mitotic index was found to increase during first phase of cell cycle (24 hr. sampling time), $20.34 \%(P<0.01)$ by GTI, $16.40 \%(P<0.01)$ by GI and $16.48 \%(P<0.01)$ by GTI+GI mixture, respectively (compared to positive control Gr.IV), indicative of their anticytotoxicity towards malathion (Table
2). The incidence of aberrant cells, which were found to be $38.80 \pm 1.241$ in malathion treated animals, was reduced to $30.80 \pm 1.113$ by GTI, $29.20 \pm 0.583$ by GI and $30.40 \pm 0.927(P<0.01)$ by GTI+GI mixture (Table 2). A decrease in the number of aberrations per cell, both chromosome and chromatic type was observed in GTI, GI and GTI+GI pretreated and malathion post-treated groups. The calculated suppressive effect was $20.62 \%$ by GTI, $24.74 \%$ by GI and $21.65 \%$ by GTI+GI mixture, respectively (Fig. 1).

During second phase of cell cycle (48 hr sampling time) the incidence of all types of chromosomal aberrations and aberrant cells in positive control group, was found to be relatively low (37.60\% and $35.20 \%$, respectively, $P<0.01$ ) but significantly higher than control group (Tables 1\&2 and Fig. 1). The cytotoxic potential of malathion was still evident in Gr.IV, as there was a significant decrease in mitotic index $(56.93 \%, P<0.01)$. In Gr.II and Gr.III, no significant increase in aberrant cells and decrease in mitotic index was observed when compared to Gr.I, further indicating a non-mutagenic and non-cytotoxic response of green tea and ginger extracts (Tables 1\&2). The incidence of aberrant cells was found to be $35.20 \pm 0.663$ in Gr.IV, but declined to $26.80 \pm 1.020 P<0.01$ in Gr.V, $27.20 \pm$ $0.917 \bar{P}<0.01$ in Gr.VI and $25.80 \pm$ $0.735 P<0.01$ in Gr.VII, respectively (Fig. 1). The chromosomal and chromatid type aberrations per cell were also inhibited by GTI, GI and GTI+GI pretreatment. Mitotic index at $48 \mathrm{hr}$ sampling time, when compared with Gr.IV was found to be increased by $17.18 \%, 11.10 \%$ and $14.01 \%$ in Gr.V, Gr.VI and Gr.VII, respectively. The 


\section{Ekram Hashim and Abdella}

inhibition of $23.86 \%$ in Gr.V, $22.73 \%$ in Gr.VI and $26.70 \%$ in Gr.VII of GTI, GI and GTI+GI pretreatment, respectively, against malathion induced cytogenetic damage was recorded (Fig. 1).

\section{DISCUSSION}

A considerable emphasis is being laid down on the use of dietary constituents as chemoprotective measure for control of genetic diseases (Mitscher et al 1996).
Bone marrow cytogenetics is a useful short-term technique, for elucidating the mechanism as well as to identify the substances for their clastogenic and anticlastogenic activity. Majority of the mutagenic/carcinogenic compounds e.g. polycyclic aromatic hydrocarbons, acts by generating electrophillic intermediates by microsomal enzymatic reactions causing mutation. These compounds gen- erate alkylating metabolites. Following 
Arab Univ. J. Agric. Sci., Ain Shams Univ., Cairo, 13(3), 1019-1031, 2005

Table 1. Protecting effects of green tea and ginger extracts pretreatment on malathion induced different types of chromosomal aberrations in mouse bone marrow cells



1- Plant Protection Department, Faculty of Agriculture, Cairo University, Fayoum Branch, Fayoum, Egypt

2- Zoology Department, Faculty of Science, Cairo University, Beni-Sweef Branch, Beni-Sweef, Egypt 


\section{Ekram Hashim and Abdella}

Number of metaphase cells analyzed per animal group $=250$ cells

Chr.B. $=$ Chromatid Breakage Cent. Att. $=$ Centromeric Attenuation Cent. Fu. $=$ Centric Fusion E.E.Ass. $=$ End to End Association

Polp. $=$ Polyploidy $\quad$ Endom. $=$ Endomitosis

Gr.I $=$ Negative control $\quad$ Gr.II $=$ Tea control

Gr.III $=$ Ginger control

Gr.IV $=$ Malathion positive control $\quad$ Gr.V $=$ Tea + malathion $\quad$ Gr.VI $=$ Ginger + malathion

Gr.VII $=$ Tea + ginger + malathion 


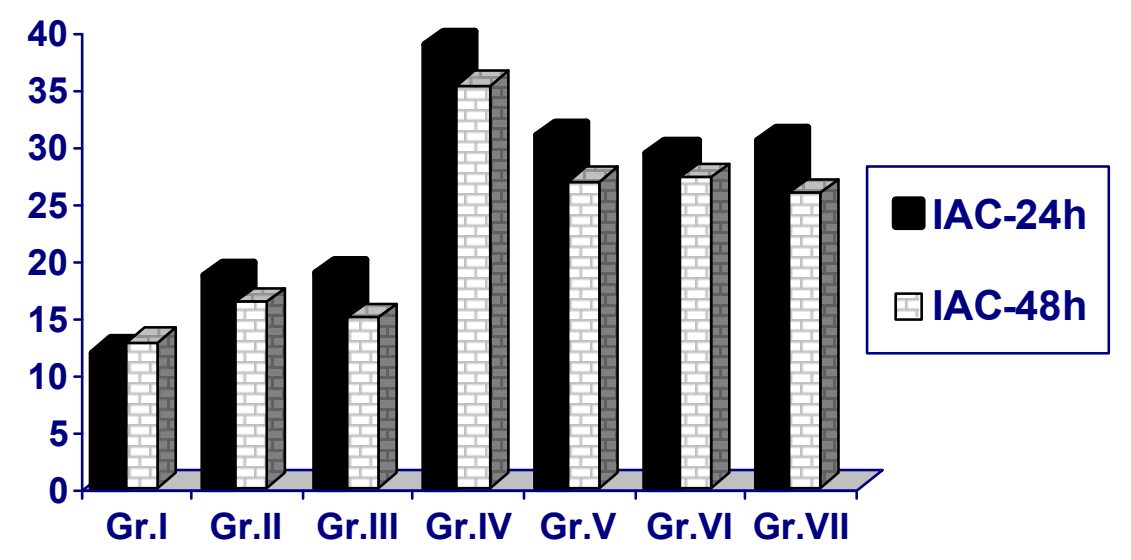

(B)

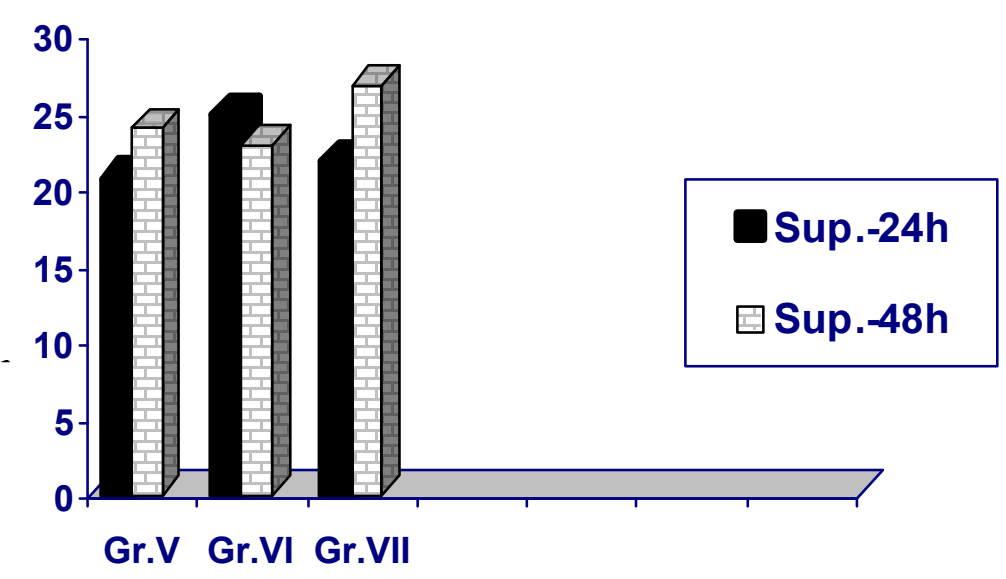

Fig. 1. Antimutagenic activity of green tea and ginger extracts in albino mice.

(A) Incidence of aberrant cells (IAC) at sampling times $24 \mathrm{~h}$ and $48 \mathrm{~h}$,

(B) Suppressive effect (Sup.) of GTI, GI and GTI + GI on chromosomal aberrations at sampling times $24 \mathrm{~h}$ and $48 \mathrm{~h}$ 
Arab Univ. J. Agric. Sci., Ain Shams Univ., Cairo, 13(3), 1019-1031, 2005

biological activation, resulting in formation of mutant cells (Vainio et al 1992 and Schurz et al 2000). Antigenotoxic agents especially those present in natural substances acts through different cellular pathways involving endogenous sequestration of mutagens by various enzymes (Shukla and Taneja, 2002).

The recorded results indicated, that animals treated once with the organophosphorous insecticide, malathion, at dose $230 \mathrm{mg} / \mathrm{kg}$ b.w. (Gr.IV), several-fold increase in the different types of chromosomal aberrations and frequency of aberrant cells with significant decrease in mitotic index were observed. This agrees with the previously reported ability of organophosphorous insecticides to produce chromosome aberrations (Furlong et al 1993; Au et al 1999; Blasiak et al 1999; Heddle et al 1999 and Giri et al 2002). The significant increase in the chromosomal abnormality and the significant decrease in the mitotic index may be due to gene damages. Since the organophosphorous insecticides are chemical alkylating agents (Wild 1975 and Garaj-Vrhovac and Zeljezic, 2002) alkylation of DNA bases either directly or indirectly via protein alkylation, is probably involved in the DNA disintegration (Green et al 1974, Flora, 1998 and Shukla and Taneja, 2002).
The present investigation revealed that the antimutagenic potential of green tea and ginger extracts against chromosomal damage, was induced by malathion. Earlier studies conducted with green tea, presence of many polyphenolic compounds, (-)-epigallocatechin gallate (EGCG), is believed to be a key active constituent in terms of cancer chemopreventive potential (Conney et al 1997 and Surh, 1999). The strong antioxidative activity retained in this polyphenol has been confirmed in numerous in vivo and in vitro studies (Aucamp et al 1997 and Soliman and Mazzio, 1998), which appears to contribute in part to the antimutagenic and anticarcinogenic effects of green tea. Also, Surh, (1999) and Jodoin et al (2002) indicated that, Tea consumption has been shown to moderately induce glutathione $S$-transferase, UDPglucuronosyl transferase, NADPHquinone oxidoreductase, and antioxidant enzymes, all of which could enhance the elimination of carcinogens.

While the oleoresin from rhizomes of ginger contains [6]-gingerol (1-[4'hydroxy-3'-methoxyphenyl]-5-hydroxy3 -decanone) and its homologs as pungent ingredients, that have been found to possess many interesting pharmacological and physiological activities, such as antiinflammatory, analgesic, antipyretic, antihepatotoxic, and cardiotonic effects (Mustafa et al 1993). Gingerol has been

1- Plant Protection Department, Faculty of Agriculture, Cairo University, Fayoum Branch, Fayoum, Egypt

2- Zoology Department, Faculty of Science, Cairo University, Beni-Sweef Branch, Beni-Sweef, Egypt

(Received March 31, 2005)

(Accepted May10, 2005) 
found to possess substantial antioxidant activity, as determined by inhibition of phospholipid peroxidation induced by the $\mathrm{FeCl}_{3}$-ascorbate system (Aeschbach et al 1994). The antioxidative properties of gingerol and other constituents of ginger have been confirmed in various in vitro and in vivo test systems (Kikuzaki et al 1994). Gingerol also exerts an inhibitory effect on xanthine oxidase (Chang et al 1994) responsible for generation of superoxide anion.

The results of the present study revealed that, GTI, GI and GTI+GI could exert different anticytotoxic and antimutagenic effects during both phases of cell cycle. However, GTI exerted the highest protective level at $24 \mathrm{~h}$ sampling time (Gr.V), but GTI+GI mixture (Gr.VII) at $48 \mathrm{~h}$ sampling time. While high suppressive effects and low incidence of aberrant cells were observed at $48 \mathrm{~h}$ sampling time indicative of greater detoxification ability in later stages.

The present study concluded that, malathion used as commercial product can be considered as a genotoxic substance in vivo, because it produces, DNA disturbances, such as DNA breakage at sites of oncogenes or tumor suppressor genes, thus playing a role in the induction of malignancies in individuals exposed to this agent. Therefore, malathion can be regarded as a potential mutagen/carcinogen and requires further investigations. Also the study concluded that, each of green tea and ginger extracts exert antimutagenic effects of varied potency, dependent on sampling time. While the mixture of green tea and ginger extracts exerts the highest protective potency. Hence the oral administration of GTI, GI and $\mathrm{GTI}+\mathrm{GI}$ is found to be capable of preventing chromosomal aberrations caused by malathion. The protective effects of GTI, GI and GTI+GI towards malathion induced cytotoxic and cytogenetic damage implies as a good marker of their antimutagenic and antineoplastic activity.

\section{REFERENCES}

Aeschbach, R.; J. Loliger; B.C. Scott; A. Murcia; B. Butler; B. Halliwell and O.I. Aruoma (1994). Antioxidant actions of thymol, carbacrol, 6-gingerol, zingerone and hydroxytyrosol. Food and Chemical Toxicology 32: 31-36. Amer S.M.; M.A. Fahmy; F.A. Aly and A.A. Farghaly (2002). Cytogenetic studies on the effect of feeding mice with stored wheat grains treated with malathion. Mutat. Res. 513 (1-2): 1-10. Au, W.W.; C.H. Sierra-Torres and N. Cajas-Salazar (1999). Cytogenetic effects from exposure to mixed pesticides and the influence from genetic susceptibility. Environ. Health Perspect. 107: 501-505.

Aucamp, J.; A. Gaspar; Y. Hara and Z. Apostolides (1997). Inhibition of xanthine oxidase by catechins from tea (Camellia sinensis). Anticancer Res. 17: 4381-4385.

Bailey, G. and D. Williams (1993). Potential mechanisms for food-related carcinogens and anticarcinogens. Food Technol. 47: 105-118. Blasiak, J.; P. Jaloszynski; A. Trzeciak and K. Szyfter (1999). In vitro studies on the genotoxicity of the organophosphorus insecticide malathion and its two analogues. Mutat. Res. 30: 275-283. Blasiak, J. and D. Stankowska (2001). Genotoxicity of malaoxon: Induction of oxidized and methylated bases and 
protective effect of a-tocopherol. Pest Biochem. Physiol. 71: 88-96. Chang, W.S.; Y.H. Chang; F.J. Lu and H.C. Chiang (1994). Inhibitory effects of phenolics on xanthine oxidase. Anticancer Res. 14: 501-506. Conney, A.A.; Y.R. Lou; J.G. Xie; T. Osawa; H.L. Newmark; Y. Liu; R.L. Chang and M.T. Huang (1997). Some perspectives on dietary inhibitors of carcinogenesis; studies with curcumin and tea. Proceedings of the Society of Experimental Biology and Medicine 216: 234-245.

Contreras, H.R. and R. BustosObregon (1999). Morphological alterations in mouse testis by a single dose of malathion. E.J. Exp. Zool. 284(3): 355359.

DeMarini, D.M. (1998). Dietary interventions of human carcinogenesis. Mutat. Res. 400: 457-465.

Ernst, P. (2002). Pesticide exposure and asthma. Am. J. Respir. Crit. Care Med. 165: 563-564.

Flore, S.D. (1998). Mechanism of inhibitors of mutagenesis and carcinogenesis, Mutat. Res. 402: 151158.

Fujiki, H.; S. Yoshizawa; T. Horiuchi; M. Suganuma; J. Yatsunami; S. Nishiwaki; S. Okabe; R. NishiwakiMatsushima; T. Okuda and T. Sugimura (1992). Anticarcinogenic effects of (-)-epigallocatechin gallate.

Prev. Med. 21: 503-509.

Fujiki, H.; M. Suganuma; A. Komori; J. Yatsunami; S. Okabe; T. Ohta and E. Sueoka (1994). A new tumor promotion pathway and its inhibitors.

Cancer Detect. Prev., 18: 1-7.

Fujiki, H.; M. Suganuma; S. Okabe; A. Komori; E. Sueoka; N. Sueoka; T.
Kozu and Y. Sakai (1996). Japanese green tea as a cancer preventive in humans. Nutr. Rev. 54: S67-S70. Furlong, C.E.; L.G. Costa; C. Hassett; R.M. Richter; J.A. Sundstorm; D.A. Adler; C.M. Disteche; C.J. Omiecinski; C. Chaplin and J.W. Crabb (1993). Human and rabbit paraoxonase: Cloning, sequencing, mapping and role of polymorphism in organophosphate detoxification. Chem. Biol. Interact. 87: 35-48.

Garaj-Vrhovac, V. and D. Zeljezic (2002). Assessment of genome damage in a population of Croatian workers employed in pesticide production by chromosomal aberration analysis, micronucleus assay and Comet assay. $\boldsymbol{J}$. Appl. Toxicol. 22 (4): 249-55.

Giri, S.; A. Giri; G.D. Sharma and S.B. Prasad (2002). Induction of sister chromatid exchanges by cypermethrin and carbosulfan in bone marrow cells of mice in vivo. Mutagenesis 18 (1): 53-58. Green, M.L.; A.S. Metcalf; C.F. Arleft; S.A. Harcourt and A.R. Lehmann (1974). DNA strand breakage caused by dichlorovos methyl methanesulphonate and siodocetamide in Escherichia coli and cultured Chinese hamaster cells. Mutat. Res. 28: 405-411. Gupta, S.; B. Saha and A.K. Giri (2002). Comparative antimutagenic and anticlastogenic effects of green tea and black tea a review. Mutat. Res. 512 (1): 37-65.

Heddle, J.A.; J.A. Moody; L.U. Thompson; D.K. Torous and T. Grace (1999). New approaches to antimutagenesis. J. Env. Path. Tox. Oncol. 18: 95-101.

Ho, C.T.; Q. Chen; H. Shi; K.Q. Zhang and R.T. Rosen (1992). Antioxidative effect of polyphenol extract prepared 
from various Chinese teas. Prev. Med. 21: 520-525.

Jodoin, J.; M. Demeule and R. Béliveau (2002). Inhibition of the multidrug resistance P-glycoprotein activity by green tea polyphenols. Biochem. Biophys. Acta 1542 (1-3):149159.

Kikuzaki, H.; Y. Kawasaki and N. Nakatani (1994). Structure of antioxidative compounds in ginger, in: Ho, C.T.; T. Osawa; M.T. Huang; R.T. Rosen (eds.), Food Phytochemicals for Cancer Prevention II, pp. 237-243. Am. Chem. Soc., Washington, DC.

Kohlmeier, L.; K.G. Weterings; S. Steck and F.J. Kok (1997). Tea and cancer prevention: an evaluation of the epidemiologic literature. Nutr. Cancer 27(1):1-13.

Komori, J.; S. Yatsunami; S. Okabe; K. Abe; M. Hara; S. Suganuma; J. Kim and H. Fujiki (1993).

Anticarcinogenic activity of green tea polyphenols. Jpn. J. Clin. Oncol. 23: 186-190.

Krul, C.; A. Luiten-Schuite; A. Tenfelde; B. Ommen; H. Verhagen and R. Havenaar (2001). Antimutagenic activity of green tea and black tea extracts studied in a dynamic in vitro gastrointestinal model. Mutat. Res. 474(1-2): 71-85.

Lin, Y.L. and J.K. Lin (1997). (-)epigallocatechin-3-gallate blocks the induction of nitric oxide synthase by down-regulating lipopolysaccharideinduced activity of transcription factor nuclear factor-KB. Mol. Pharmacol. 52: 465-472.

Meulenberg, E.P. (2002). A new test to identify endocrine disruptors using sexhormone-binding globulins from human serum. Eur. J. Lipid Sci. Technol. 104: 131-136.

Mitscher, L.A.; H. Tilkepalli; E. McGhee and D.N. Shankel (1996). Natural antimutagenic agents. Mutat. Res. 350: 143-152.

Mustafa, T.; K.C. Srivastava and K.B. Jensen (1993). Drug development report (9): pharmacology of ginger, Zingiber officinale. J. of Drug Development 6: 25-39.

Preston, R.J.; B.J. Dean; S. Galloway; H. Holden; A. Mc-fee and M. Shelby (1987). Mammalian in vivo cytogenetic assays-analysis of chromosomal aberrations in bone marrow cells. Mutat. Res. 189: 157-165.

Salvadori, D.M.; L.R. Ribeiro; C.A. Pereira and W. Becak (1988). Cytogenetic effects of malathion insecticide on somatic and germ cells of mice. Mutat Res. 204 (2): 283-287. Schurz, F.; M. Sabater,-Vilar and J. Fink-Gremmels (2000). Mutagenicity of mercury chloride and mechanisms of cellular defence: the role of metal-binding proteins. Mutagenesis 15(6): 525-530. Shukla, Y. and P. Taneja (2002). Antimutagenic effects of garlic extract on chromosomal aberrations. Cancer Lett. 176: 31-36.

Soliman, K.F. and E.A. Mazzio (1998). In vitro attenuation of nitric oxide production in C6 astrocyte cell culture by various dietary compounds. Proc. Soc. Exp. Biol. Med. 218: 390-397. Surh, Y.J. (1999). Molecular mechanisms of chemopreventive effects of selected dietary and medicinal phenolic substances. Mutat. Res. 428: 305-327.

U.S. Environmental Protection Agency (2000). Malathion: Human Health Risk Assessment for the Reregistration 
14

Ekram Hashim and Abdella

Eligibility Decision. pp. 14-15. U.S.

EPA. Office of Prevention, Pesticides and

type tumor promoters. Carcinogenesis

Toxic Substances North, Carolina .

14: 1195-1201.

Weisburger, J.H. (1999). Tea and

Vainio, H.; P.N. Magee; D.B. Mchealth: the underlying mechanisms. Proc.

Gregor and A.J. Mc-Michael (1992). Mechanisms of Carcinogenesis in Risk Identification, WHOIARC Scientific Publications, No. 116, Lyon, France. Wei, H. and K. Frenkel (1993).

Relationship of oxidative events and DNA oxidation in SENCAR mice to in vivo promoting activity of phorbol esterSoc. Exp. Biol. Med. 220: 271-275. Wild, D. (1975). Mutagenicity studies on organophosphorous insecticides. Mutat. Res., 32: 339.

Yoshioka, H.; H. Kurosaki; K. Yoshinaga; K., Saito and H., Yoshioka (1997). Beta-ray-induced scission of DNA in treated water and protection by a green tea percolate and (-)epigallocatechin gallate. Biosci. Biotechnol. Biochem. 61: 1560-1563. 
Arab Univ. J. Agric. Sci., Ain Shams Univ., Cairo, 13(3), 1019-1031, 2005

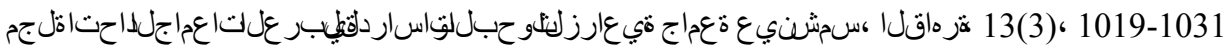
، 2005



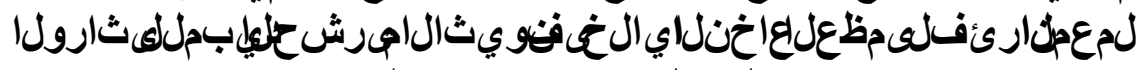



]70[

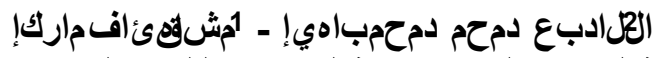

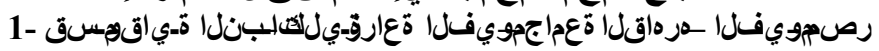

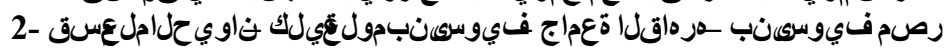

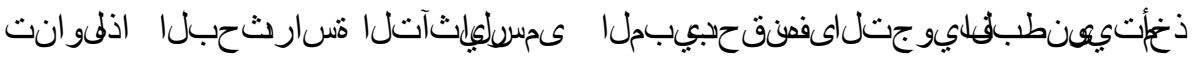



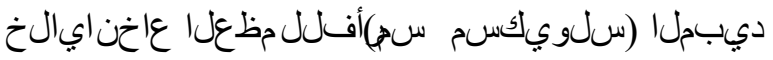

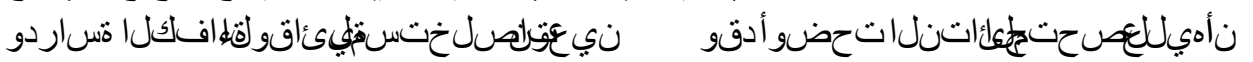

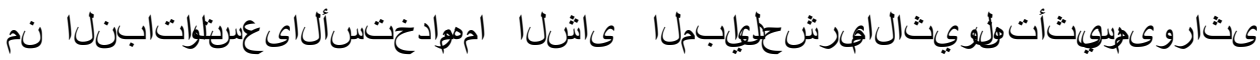

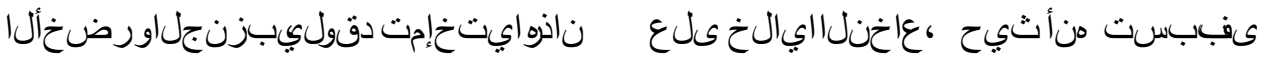

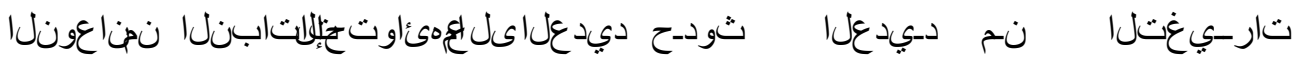



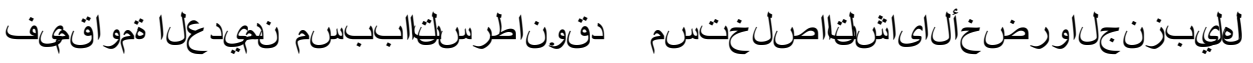

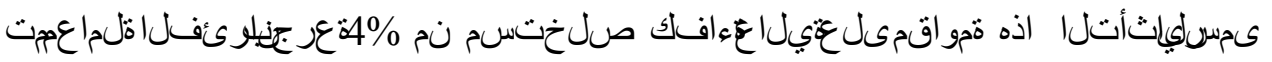

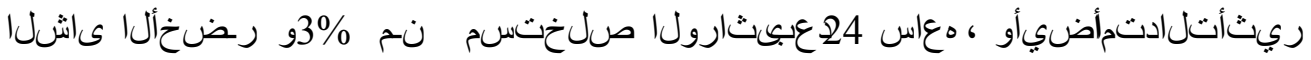

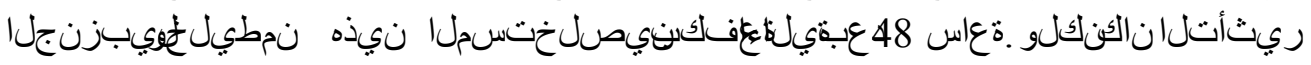



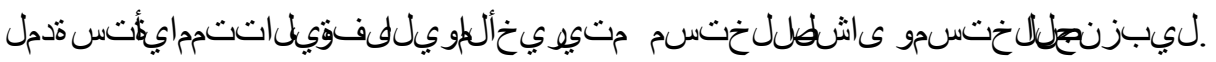

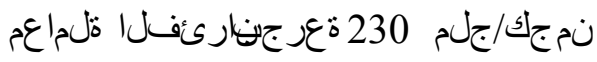

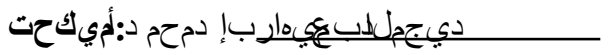

1- Plant Protection Department, Faculty of Agriculture, Cairo University, Fayoum Branch, Fayoum, Egypt

2- Zoology Department, Faculty of Science, Cairo University, Beni-Sweef Branch, Beni-Sweef, Egypt

(Received March 31, 2005)

(Accepted May10, 2005) 
Arab Univ. J. Agric. Sci., Ain Shams Univ., Cairo, 13(3), 1019-1031, 2005

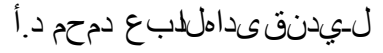

1- Plant Protection Department, Faculty of Agriculture, Cairo University, Fayoum Branch, Fayoum, Egypt

2- Zoology Department, Faculty of Science, Cairo University, Beni-Sweef Branch, Beni-Sweef, Egypt

(Received March 31, 2005)

(Accepted May10, 2005) 